\title{
Novas perspectivas para uma sistematização das teorias do jornalismo
}

\section{Carlos Franciscato}

Doutor; Universidade Federal do Sergipe

cfranciscato@uol.com.br

\section{Resumo}

Os estudos sobre jornalismo possuem pelo menos um século de produção científica regular, embora seu lugar no universo acadêmico dependa ainda de disputas institucionais e sofra questionamentos sobre sua constituição como quadro teórico, disciplina ou campo de estudos. Se, por um lado, a discussão tem raízes epistemológicas a respeito dos elementos que dão solidez, densidade e convergência a teorias no tratamento de um fenômeno específico, é possível também conduzir esta reflexão olhando para a constituição e configuração histórica desses estudos. A proposta deste artigo é fazer um duplo movimento de leitura dessa obra intelectual sobre o jornalismo: primeiro, entender esse movimento histórico, suas raízes e trajetórias; depois, considerar uma perspectiva contemporânea, tomando por base questões sobre sua disciplinaridade. Este é um trabalho de caráter dedutivo, operando uma sistematização teórico-conceitual de tendências e traços de caráter mais geral desses estudos, com base em uma bibliografia de referência em jornalismo.

\section{Palavras-chave}

Teorias do Jornalismo. História da Ciência. Disciplinaridade. Campo científico. Progresso científico.

\section{Introdução}

A construção do pensamento acadêmico sobre o jornalismo tem acompanhado a constituição deste fenômeno desde suas experiências iniciais a partir do século XVII. Jorge Pedro Souza (2007) localiza, em intelectuais a partir daquele século, uma abordagem das transformações que a sociedade passou com o surgimento do jornalismo e a necessidade de sua compreensão e crítica como fenômeno e discurso. Dois autores são considerados inaugurais 
para o desenvolvimento de uma teorização sobre o jornalismo: Tobias Peucer, que defendeu sua tese de doutorado sobre jornalismo em 1690 na Universidade de Leipzig, e Otto Groth (2011), que desenvolveu, na primeira metade do século XX, um conjunto de obras que contêm um conhecimento denso, conceitual, sistemático e autônomo sobre o jornalismo.

Beatriz Marocco e Christa Berger (2006; 2008) conseguiram reunir, em dois volumes, um compêndio de textos clássicos de pensadores do início do século XX que fundamentaram uma compreensão teórica sobre o jornalismo. Nestas fases iniciais da pesquisa, é possível identificar o esforço pela formulação de conceitos próprios para explicar a especificidade do fenômeno jornalístico.

Löffelholz e Rothenberger (2011) constituíram um quadro explicativo procurando apresentar um movimento histórico de produção de conhecimento em jornalismo. Eles sistematizaram um grupo de disciplinas científicas que tem contribuído para configurar o jornalismo em sua especificidade em mais de um século de estudos (Figura 1). Além de indicar as vertentes disciplinares, a análise dos autores propõe fases dominantes nas pesquisas em jornalismo, alcançando modelos complexos contemporâneos.

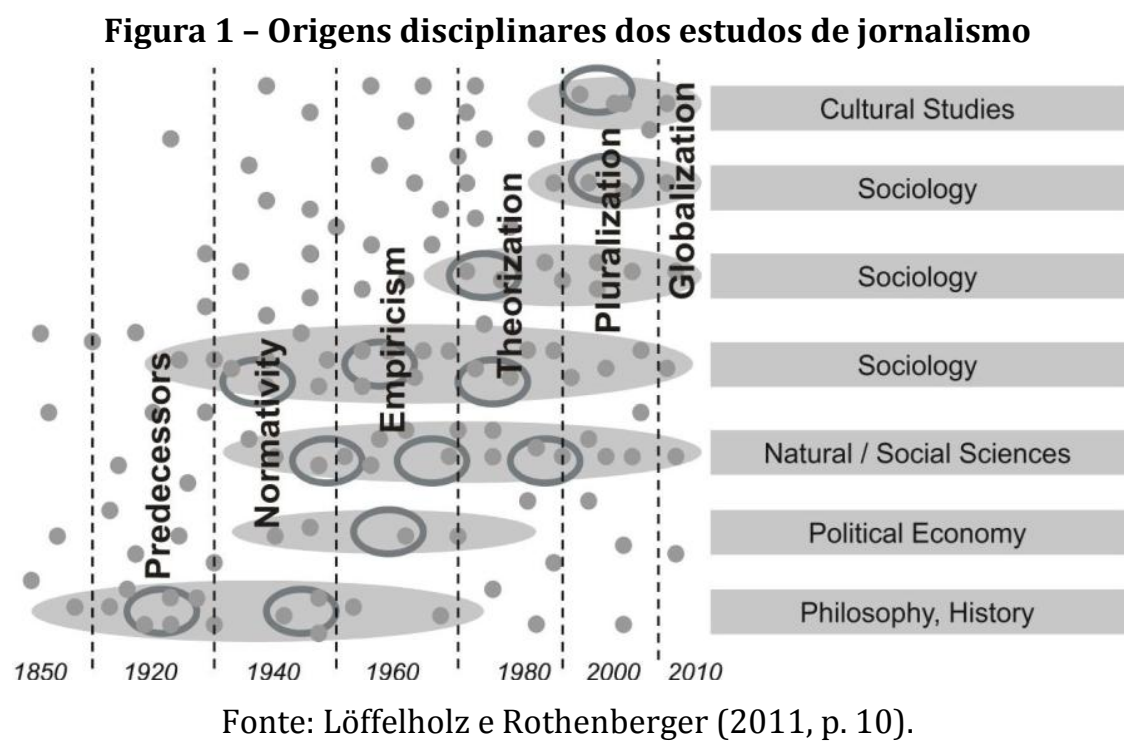

0 quadro indica tanto a presença predominante de disciplinas clássicas que fundamentaram a produção de estudos sobre o jornalismo em determinados períodos como sinaliza, dentro das elipses em cinza claro, certas formas de tratamento do objeto. Algumas dessas perspectivas são apresentadas por Löffelholz e Rothenberger (2011, p. 10-11): individualismo normativo com origens na filosofia e na história, teorias materialistas de mídia derivadas da economia política, empiricismo analítico (e legitimístico) com base nas ciências 
naturais e sociais, teorias de ação, teorias de sistemas e teorias social-integrativas baseadas em abordagens sociológicas, e estudos culturais.

Neste artigo, procuramos compreender a constituição dos estudos sobre jornalismo aplicando uma perspectiva trazida pelos estudos de história e filosofia das ciências de viés historicista. Adotamos como interpretação central desta perspectiva a obra de Larry Laudan, particularmente suas teses sobre a ciência como uma atividade de resolução de problemas, as tradições de pesquisa científica e o modelo de rede triádica para entender o progresso científico.

Aplicaremos este esquema conceitual sobre os estudos de jornalismo, valorizando dois aspectos: em primeiro lugar, sua construção observada de um ponto-de-vista histórico. Para isso, adotaremos, como textos ilustrativos de interlocução, o artigo de Martin Löffelholz e Liane Rothenberger Continuum eclético, disciplina distinta ou subdomínio dos estudos de comunicação? (2011) e o livro de Barbie Zelizer Taking journalism seriously (2004). Buscamos nestes trabalhos não uma sistematização exaustiva da história dos estudos sobre o jornalismo, mas sim seus olhares para compreender esse movimento histórico.

O segundo aspecto, complementar a este, é conduzir uma discussão sobre a disciplinaridade do pensamento científico em jornalismo. Continuamos operando dentro do quadro teórico de Laudan, mas, ao aplicá-lo às pesquisas em jornalismo, consideramos oportuno trazer o aporte teórico, de origem epistemológica, sobre a natureza disciplinar, interdisciplinar, multidisciplinar ou transdisciplinar da construção do conhecimento científico. Isto porque, na articulação entre os dois aspectos, pretendemos refletir sobre a dimensão rica e tensa da constituição do pensamento acadêmico em jornalismo durante o século XX e início do XXI, em que predominam ao menos dois movimentos diferenciados: um em busca da formação de um corpus específico de conhecimento sobre o jornalismo; outro, estudando o jornalismo a partir de disciplinas ou abordagens consolidas, executando movimentos transversais na abordagem do jornalismo como objeto de pesquisa.

Parece-nos que o acúmulo teórico obtido nos estudos sobre o progresso da ciência considerando sua historicidade auxilia-nos a lançar luzes para um entendimento da formação e consolidação dos estudos sobre jornalismo em um contexto acadêmico de busca por validação científica. Este artigo executa, então, um trabalho de caráter teórico, estimulando reflexões e sistematizações de tendências e traços de caráter mais geral desses estudos, com base em uma bibliografia de referência em jornalismo. Reforçamos que a realização de um estudo historiográfico sobre o pensamento em jornalismo implica considerar duas perspec- 
tivas articuladas: a temporalidade das construções teóricas e o lugar em que estas foram produzidas. Assumimos que nossa leitura da história do jornalismo é referencial, não contemplando a globalidade de autores, correntes e comunidades científicas. Uma investigação mais aprofundada demandaria o escrutínio das obras e pesquisadores considerando sua inserção nas diferentes comunidades acadêmicas das quais fazem parte, pois estas comunidades é que estabelecem expectativas e condições para o trabalho científico e para a consideração do jornalismo como objeto relevante de estudo.

A seguir, apresentaremos a discussão proposta neste artigo em três momentos: abordaremos inicialmente algumas teses centrais da obra de Larry Laudan como forma de instrumentalização teórica desta reflexão a partir da perspectiva da história e da filosofia das ciências, executando breves diálogos com outros autores. Um segundo percurso será considerar elementos da discussão sobre a disciplinaridade na ciência e o cruzamento de fronteiras. Ambas abordagens se destinam a qualificar uma argumentação sobre a sustentabilidade de um recorte teórico específico e singular nos estudos em jornalismo.

\section{Laudan: resolução de problemas, tradições científicas e rede triádica}

A aproximação com autores do campo da história e da filosofia da ciência e, em consequência, a tentativa de um recorte desta perspectiva aplicada aos estudos de jornalismo, pretende conduzir a discussão sobre a solidez, densidade, convergência, disciplinaridade ou cientificidade dos estudos em jornalismo (ou daquilo que comumente denominamos como "Teorias do Jornalismo") executando um esforço de buscar um olhar mais ampliado sobre esse corpo de conhecimentos, sua constituição e configuração.

Colocamos em discussão um importante e recente autor da história das ciências, Larry Laudan e, na medida do necessário, procuramos aproximá-lo nas discussões com outros pesquisadores desta perspectiva, como Thomas Kuhn, Imre Lakatos e, a partir de uma perspectiva sociológica, Pierre Bourdieu. Nossa preocupação central não é levar a reflexão deste artigo para o centro dos debates epistemológicos da história das ciências, mas nos possíveis pontos-de-contato entre suas contribuições teóricas e os caminhos seguidos pelos investigadores em jornalismo.

É importante considerar, com Trigueiro (2013, p. 3-5) que os três primeiros autores compõem a chamada "escola historicista" no campo da Filosofia da Ciência, permitindo introduzir métodos lógicos para pensar o avanço das teorias científicas ao longo do tempo. Laudan et al. (1993, p. 7) ressaltam a importância de se compreender "[...] como a ciência 
conduz sua tarefa de investigar, testar e finalmente aceitar ou rejeitar teorias.", defendendo a necessidade de se realizar um estudo sistemático dos processos de mudança e invenção de teoria na ciência. Por isso enunciam que "Todos os filósofos históricos da ciência endossam a tese metafilosófica de que a ciência é fundamentalmente uma atividade cuja racionalidade pode ser revelada somente pela investigação empírica de suas obras através do tempo." (LAUDAN et al., 1993, p. 7).

Uma das teses centrais de Laudan está expressa em sua proposta de que "A ciência é, em essência, uma atividade de resolução de problemas." (1986, p. 39). Desta, desdobram-se dois procedimentos lógicos: o primeiro é que uma teoria é testada por sua capacidade de oferecer respostas aceitáveis e satisfatórias a perguntas relevantes; o segundo é de que mérito da teoria é atribuído exatamente caso alcance soluções adequadas a problemas relevantes, em vez de sua capacidade de ser "verdadeira", "corroborada" ou "bem confirmada" (OSTERMANN et al., 2008, p. 368-9).

Se a resolução de problemas é o movimento lógico para a constituição e solidez de um conhecimento científico, precisamos entender um pouco mais o que seriam esses problemas. Laudan destaca dois tipos: empíricos e teóricos. Existem três tipos de problemas empíricos (OSTERMANN et al., 2008, p. 370-1): a) não resolvidos adequadamente por nenhuma teoria; b) já resolvidos satisfatoriamente por alguma teoria existente; e c) anômalos, não resolvidos pela teoria em questão, mas por outras teorias alternativas.

Os problemas conceituais são de dois tipos (OSTERMANN et al., 2008, p. 373-4): a) problemas internos: quando uma teoria é logicamente inconsistente e, portanto, autocontraditória. Neste caso, surgem ambiguidades ou circularidades conceituais no âmbito da teoria; b) problemas externos: quando uma teoria é logicamente inconsistente com outra teoria aceita, em decorrência de questões normativas referentes à metodologia ou de dificuldades consequentes de diferentes visões de mundo sobre as quais as teorias concorrentes se sustentam.

Assim, a resolução de problemas é a unidade básica para identificar o progresso científico. A teoria é avaliada por sua efetividade global:

Esta se determina avaliando o número e a importância dos problemas empíricos que a teoria resolve, e "subtraindo" o número e a importância das anomalias e problemas conceituais que a teoria gera. Há progresso se, e somente se, a sucessão de teorias científicas em um domínio mostra um grau crescente de efetividade na resolução de problemas (OSTERMANN et al., 2008, p. 375). 
Esta perspectiva indica um mecanismo de avaliação das teorias científicas: sua importância é medida pela capacidade em oferecer soluções adequadas aos problemas, eliminando ambiguidades, reduzindo irregularidades a uniformidades e demonstrando um potencial para prever os fenômenos (PESA; OSTERMANN, 2002). Isto significa que, para Laudan, a resolução de problemas é a base para avaliar o progresso do conhecimento científico. Uma teoria é apreciada pela quantidade e qualidade dos problemas teóricos e empíricos resolvidos. Nesta avaliação, devem ser considerados os pesos dos problemas resolvidos, sua prioridade e importância para a ciência e a sociedade.

Uma segunda tese de Laudan, importante para este artigo, refere-se às tradições de pesquisa. Segundo Pesa e Ostermann (2002, p. 91-2), tradições de pesquisa consistem tanto de crenças sobre elementos e procedimentos de investigação quanto normas epistemológicas e metodológicas sobre como se deve investigar e testar as teorias. Para esses autores, as funções fundamentais das tradições de pesquisa são: orientar na determinação de problemas pertinentes; identificar as partes de uma teoria que apresentam conflitos e devem ser modificadas; estabelecer regras para a coleta de dados e contraste das teorias e apresentar problemas conceituais que, segundo a tradição, estão em contradição com as exigências ontológicas e epistemológicas da "tradição mãe" (PESA; OSTERMANN, 2002, p. 92).

A tentativa de compreensão e explicação da ciência em Laudan passa também por uma terceira tese, a indicação de um modelo reticular da racionalidade científica, composto por uma rede triádica de três elementos da ciência articulados entre si: as teorias, os métodos e os objetivos (axiologia). Laudan aponta como esses três aspectos influenciam-se mutuamente: os métodos instrumentalizam as teorias, mas, ao fazer isso, as justificam à luz de objetivos estabelecidos. As teorias, harmonizadas aos objetivos, restringem os métodos possíveis. Outras relações poderiam ser percebidas, mas o fundamental é reconhecer que o avanço da ciência ocorre quando esta harmonização e justificação mútua conduz à elaboração de teorias mais consistentes.

É útil entender que a interpretação de Laudan para o progresso da ciência surge em contraposição às interpretações oferecidas por Thomas Kuhn em seu livro A estrutura das revoluções científicas (2009). A definição que ofereceu ao conceito de paradigma tem um efeito analítico eficaz para explicar a atuação de uma comunidade de cientistas comprometidos com movimentos de construção de consensos e sua consolidação como "ciência normal" (2009, p. 29) e, ao mesmo tempo, o surgimento de "crises" desta verdade baseada neste 
procedimento de validação do conhecimento para, em consequência, a construção de novos consensos.

Kuhn caracteriza um paradigma como um conjunto de pressupostos que proporcionam os fundamentos para a produção do conhecimento científico, na forma de leis, teorias e técnicas para aplicação e instrumentalização da produção de conhecimento que sejam aceitos e compartilhados pela comunidade científica. Em outras palavras, são "[...] realizações científicas universalmente conhecidas que, durante algum tempo, fornecem problemas e soluções modelares para uma comunidade de praticantes de uma ciência." (2009, p.13).

Quando uma comunidade científica adquire um paradigma, "adquire igualmente um critério para a escolha dos problemas que, enquanto o paradigma for aceito, podem ser considerados como dotados de uma solução possível" (Kuhn, 2009, p. 60). Nas instituições acadêmicas, o estabelecimento de um paradigma dominante se manifesta na criação de publicações especializadas, fundação de sociedade de especialistas e pela reivindicação de sua inserção nos currículos acadêmicos de estudo. Esta perspectiva recebeu críticas posteriores principalmente por dar uma ênfase excessiva na ideia de unidade interna de um paradigma, o que destoaria do desenvolvimento histórico das ciências sociais, baseado em escolas rivais normalmente enraizadas em diferenças epistemológicas. Além disso, o paradigma é concebido como um sistema fechado de premissas epistemológicas, o que não se adequa às ciências sociais, de base interpretativa, em que há variação de significados para objetos conceituais e fenômenos sociais (GIDDENS, 1996).

Imre Lakatos faz também um deslocamento em relação a Kuhn. Em vez de conceber as ciências como a sucessão de paradigmas ou teorias, Lakatos define a história das ciências como a "história dos programas de investigação científica em lugar de ser a história das teorias" ou como "a história dos quadros conceituais e da linguagem científica" (LAKATOS, 1989, p. 52). Analisar os programas de investigação científica significa evitar aprisionar o pensamento em torno das teorias como unidades analíticas para constatar o vigor científico de determinada abordagem científica. Como vimos, Kuhn adotou a perspectiva da construção e perpetuação de paradigmas como forma de estabelecer este diagnóstico de cientificidade. Lakatos se distanciará da identificação ou não de teorias e procurará olhar que a construção do conhecimento se faz por meio de um duplo movimento "heurístico". No primeiro momento, no esforço para o estabelecimento do que ele denomina como "núcleo firme" de um programa de investigação científica (LAKATOS, 1989, p. 53-4). 
Este núcleo firme seria uma espécie de princípios ou conceitos fundamentais que dão lógica e coerência a um pensamento científico, e o movimento da pesquisa deveria ser sempre o de preservá-lo e o consolidar. Assim, os cientistas, ao estabelecerem programas de investigação científica, não buscam olhar para teorias como um conjunto totalizante. Em vez disso, seu trabalho é de consolidar esse núcleo firme como caminho para solidificar e densificar um pensamento científico.

Nas pesquisas, este núcleo não poderia ser colocado em causa. "Não deve ser operado um esforço lógico para negá-lo, pelo contrário deve-se criar um cinturão protetor em torno dele." (LAKATOS, 1989, p. 54). Isto é, o que está permanentemente exposto a escrutínio científico é o que ele chama de "cinturão protetor". Então, o segundo movimento "heurístico" destina-se a construir este cinturão protetor, pois será ele que as pesquisas irão desafiar. "Os questionamentos devem ser direcionados apenas para as hipóteses localizadas neste cinturão protetor, não ao núcleo firme." (LAKATOS, 1989, p.54). Este movimento heurístico consiste de "[...] um conjunto, parcialmente estruturado, de sugestões ou pistas sobre como mudar ou desenvolver as 'versões refutáveis' do programa de investigação, sobre como modificar e complicar o cinturão protetor refutável." (LAKATOS, 1989, p.54).

\section{Fronteiras comunicacionais e seus cruzamentos}

O uso dessa perspectiva da história e filosofia da ciência para indicar os movimentos de desenvolvimento dos estudos em jornalismo e seu movimento em direção a um pretendido progresso científico demanda considerar a especificidade epistemológica desta área de conhecimento. Conforme vimos, as primeiras investigações sobre o jornalismo foram pioneiras dentro do campo dos estudos de comunicação, desenvolvendo-se com vigor já nas primeiras décadas do século XX. Entretanto, com a rápida expansão dos sistemas de comunicação, impulsionada pelas inovações tecnológicas e complexificação das sociedades, um novo campo social (conforme a perspectiva de Pierre Bourdieu) gradativamente se consolidou, o campo dos estudos de comunicação.

Paradigma e campo, assim como ciência e disciplina, têm sido termos recorrentes para tentar definir a consolidação da área acadêmica de comunicação. Os membros desta comunidade têm executado um esforço, nas últimas décadas, de constituir um campo em um nível científico, acadêmico e institucional (ROMANCINI, 2006).

Este movimento passa, no entanto, pelo enfrentamento de questões que são também de ordem epistemológica. Martino (2003, p. 84) considera que um dos motivos da desconfi- 
ança sobre a cientificidade produzida no campo da comunicação é a ampla diferença entre saberes presentes no campo, oscilando entre uma perspectiva mais prática ou aplicada da comunicação, em que seu sentido disciplinar está fundado na dimensão da atividade comunicacional, e uma perspectiva transdisciplinar, em que a comunicação é, na verdade, um espaço de reflexão que se situa além de uma disciplina compartimentalizada.

A pretensão de unidade e coesão ao campo da comunicação, seja por meio de teorias, conceitos, objetos ou metodologias minimamente consensuais, é questionada por Bolaño (2008, p. 108-110), que rejeita a possibilidade de um paradigma unificador. Ao contrário, o autor defende que o campo poderia ter melhor caracterização com o reconhecimento da existência de paradigmas em disputa permanente. Nesta perspectiva, a questão passa pelas formas de co-habitação de grupos diferenciados e sua divisão em subcampos, especializações ou disciplinas. Por disciplina, seguiremos Bourdieu: “A disciplina é definida pela posse de um capital colectivo de métodos e conceitos especializados cujo domínio constitui o requisito de admissão tácito ou implícito no campo." (2004, p. 92).

A compreensão das disciplinas no ambiente científico indica duas questões importantes para o argumento que estamos desenvolvendo: as fronteiras e as intersecções disciplinares. Bourdieu enfatiza não o aspecto epistemológico envolvido na formação de disciplinas, mas a sua natureza institucional e relacional. As disciplinas se estabilizam em ambientes institucionais (laboratórios, departamentos, revistas, congressos) e direcionam a formação de processos de certificação de competências e premiações.

De um ponto de vista histórico, o campo da comunicação no Brasil tem executado um movimento de auto-constituição em uma dimensão epistemológica e acadêmicoinstitucional (departamentos, faculdades, congressos, associações, periódicos científicos, cursos de graduação, expansão de programas de pós-graduação etc). Nesse aspecto acadêmico-institucional, há um duplo movimento histórico. Por um lado, pela unificação do campo em eixos comuns que identificam as práticas profissionais da área como práticas comunicacionais e, na pós-graduação, como o estabelecimento de critérios comuns para criação e avaliação de programas de pós-graduação.

Por outro lado, há um movimento de diversificação da área, em um esforço de constituição de subcampos especializados que reflitam a pluralidade de conhecimentos e perspectivas teóricas comunicacionais, assim como relações com outros campos do conhecimento científico. Na relação do campo da comunicação com outros campos científicos, Hohlfeldt 
(2004) não crê na permanência de uma situação hierarquizada, de dependência da comunicação com os demais campos, mas em uma "dialogia plena".

Nesta linha de raciocínio, os estudos de jornalismo poderiam ser considerados como um subcampo, ou uma especialização, dentro da área da comunicação. É desta forma que Löffelholz e Rothenberger (2011) inserem essa corrente de investigação, ao questionar-se sobre suas possibilidades disciplinares, com epistemologias específicas, ou multidisciplinares:

Do nosso ponto de vista, os estudos de jornalismo seriam beneficiados no seu papel de subdomínio dado que os estudos de comunicação reúnem todas as áreas de pesquisa relacionadas com a mídia e comunicação, incluindo o jornalismo. Tanto os estudos de jornalismo quanto os estudos de comunicação têm estreitas ligações com a sociologia, psicologia, tecnologia da informação, linguística, literatura, ciência política e história, entre outros. Isto dá aos estudos de jornalismo a oportunidade de fazer uso das suas abordagens e experiências interdisciplinares apesar de seu status subdisciplinar. Além disso, a perspectiva mais ampla dos estudos de comunicação facilita a superação das fronteiras culturais, nacionais e disciplinares possibilitando uma verdadeira pesquisa global em jornalismo (WEAVER; LÖFFELHOLZ, 2008, p. 8). Finalmente, os estudos de comunicação transcendem diversas disciplinas e visam se tornarem uma das matérias acadêmicas axiais do século 21. Isto não é um obstáculo, mas uma oportunidade para os estudos de jornalismo (LÖFFELHOLZ; ROTHENBERGER, 2011, p. 28).

A perspectiva de afirmação como subdomínio da comunicação, no entanto, não dá conta em descrever e explicitar movimentos específicos executados pelos pesquisadores em jornalismo ao tentarem compreender com mais densidade e profundidade as características do seu objeto de estudo. Em pesquisa anterior (FRANCISCATO, 2013), fizemos uma leitura dos estudos de referência sobre a notícia e percebemos um duplo movimento: por um lado, o esforço de constituição de um conhecimento original, singular, convergente e articulado sobre a notícia, que se recortava das leituras gerais das abordagens comunicacionais; por outro lado, a percepção de um esforço intencional de transversalidade na investigação, combinando inter, multi e transdisciplinaridade para agregar interpretações e formas de tratamento sedimentados por outras áreas de conhecimento.

\section{Revisitando os estudos sobre jornalismo}

O uso dessa perspectiva da história e filosofia da ciência oferece-nos novos elementos para analisar os movimentos de constituição dos estudos sobre jornalismo. Utilizaremos sistematizações sobre a constituição do campo do jornalismo produzidas por autores como 
Löffelholz e Rothenberger (2011) e Zelizer (2004) para indicar novos olhares que possibilitem ganhos interpretativos às propostas dos autores, utilizando-se principalmente do conjunto categorial formulado por Larry Laudan e o colocando em diálogo como outras propostas interpretativas apresentadas anteriormente.

\subsection{O jornalismo como problema de pesquisa científica}

Aqui, recuperamos Laudan em sua tese de que a ciência é basicamente uma atividade de resolução de problemas. Neste modelo, a teoria deve ser capaz de oferecer respostas aceitáveis e satisfatórias a perguntas relevantes, e seu mérito é julgado exatamente pelo grau em que se desincumbe dessa tarefa.

Há um primeiro indicativo de adequação: as teorias do jornalismo foram desenvolvidas como tentativas de resolução de problemas conceituais e empíricos em determinadas épocas, conforme definições das comunidades científicas predominantes que cada fase da ciência. É reconhecível que, no desenvolvimento histórico do pensamento sobre o jornalismo, as manifestações concretas do objeto de estudo (o fenômeno jornalístico e suas intensas relações no ambiente social) têm oferecido à academia um leque de problemas, principalmente em decorrência dos efeitos intensos que o jornalismo produz para a compreensão e ação no mundo por grande parte da população.

Assim, pesquisar em jornalismo tem sido uma resposta a uma demanda da experiência do jornalismo na sociedade. Os estudos em jornalismo debruçam-se predominantemente, então, sobre problemas empíricos não satisfatoriamente investigados por outros quadros teóricos: surgem e se consolidam para dar respostas a problemas socialmente relevantes cuja explicações de teorias alternativas não atendem ou são consistentes com as demandas.

É compreensível, portanto, que, por este viés de leitura do conhecimento produzido no jornalismo, os estudos de Adelmo Genro Filho e Lorenzo Gomis podem ter sido provocados por uma aguda percepção dos autores sobre as manifestações do jornalismo, levando-os a pensar sobre sua natureza. No caso de Adelmo, seu esforço é também o de enfrentar um problema conceitual, manifestado por sua crítica à inadequação das teorias dominantes no campo comunicação na metade do século XX para explicar o jornalismo e na forma com que ele contrapõe a ela um quadro conceitual marxista, reformulando e desenvolvendo sua aplicabilidade sobre o jornalismo. 


\subsection{Tradições de pesquisa nos estudos sobre jornalismo}

Além de o uso da perspectiva da resolução de problemas apresentar-se como promissora aos estudos em jornalismo, outra tese rica do autor é a das tradições de pesquisa enquanto normas epistemológicas e metodológicas sobre como se deve investigar e testar as teorias, orientando, identificando e estabelecendo regras com base em uma base epistemológica que dê unidade mínima às teorias.

De imediato, há um problema central nos estudos em jornalismo: não é possível falar em tradições de pesquisa na história do jornalismo se aplicarmos este aspecto normativo de conformação do campo a uma unidade mínima, se considerarmos as sistematizações feitas por Löffelholz e Rothenberger (2011) e Zelizer (2004). Em ambas, o movimento multidisciplinar é dominante no campo, haja vista a indicação explícita de disciplinas consolidadas (sociologia, ciências da linguagem, ciências políticas, estudos culturais etc) como alimentadoras de boa parte das pessoas. Por esses autores, a historicidade dos estudos em jornalismo está atrelada ao movimento histórico dessas disciplinas em seu próprio desenvolvimento teórico e metodológico.

Zelizer (2004) havia localizado cinco disciplinas que seriam, ainda hoje, os fundamentos teóricos e metodológicos das pesquisas em jornalismo: Sociologia, História, Estudos de linguagem, Ciência Política e Estudos culturais. Machado (2006) identifica nesta abordagem de Zelizer uma ausência em empreender um esforço de construção disciplinar de um conceito e de uma perspectiva específica de estudos em jornalismo, optando pela abordagem multidisciplinar. Ou seja: essas disciplinas geram tematizações específicas para explicar o fenômeno jornalístico, em uma aproximação que pode ser sistemática ou circunstancial, mas restrita a interpretações ou elaboração pontual de resultados, sem projeto disciplinar. Outro aspecto apontado por Machado é "a ausência da revisão da literatura da quase totalidade dos autores de fora do mundo anglo-americano" (2006, p. 5), além do tratamento pouco aprofundado a autores centrais aos estudos norte-americanos, como Robert Park.

Para pensar os estudos em jornalismo como contendo uma densidade semelhante a uma tradição de pesquisa, haveria a necessidade de avançar na constituição do pensamento sobre o fenômeno jornalístico para além de uma mera justaposição ou superposição de disciplinas. Afinal, problemas conceituais são gerados quando teorias científicas de diferentes domínios estão em tensão, algo que é recorrente nos estudos em jornalismo.

Uma possibilidade de avanço nesse desafio seria a incorporação de uma perspectiva de interdisciplinaridade nas formas como ela se expandiu e penetrou em várias áreas do 
conhecimento a partir da década de 1990. Por exemplo, na forma como Huutoniemi et al. (2010, p. 81) investigam a interdisciplinaridade por meio da superação de fronteiras conceituais e metodológicas entre campos de pesquisa, entendidos como comunidades de pesquisadores com um conjunto de questões ou problemas compartilhados, convergindo para um domínio de conhecimento.

Conforme esses autores, a perspectiva interdisciplinar busca a integração, desafiando fronteiras e estimulando intersecções, podendo ocorrer em um aspecto conceitual ou pragmático e se realizando em três níveis: a) envolvendo a integração entre dados empíricos gerados por diferentes métodos de coleta de dados, com vistas a enfrentar um problema de pesquisa interdisciplinar; b) integração ou combinação entre diferentes aplicações metodológicas, utilizadas em um contexto interdisciplinar; e c) síntese, contraste ou combinação de conceitos e modelos, ou desenvolvimento de novas aplicações teóricas entre mais de um campo científico.

Essa busca por coerência e unidade mínima teórica é uma forma de superar uma fragilidade desses estudos ao creditarem sua identidade nas características peculiares do fenômeno que é seu objeto de estudo. É certo que os estudos de jornalismo dedicam-se a um objeto singular (o jornalismo), mas isto não é suficiente para demarcar a especificidade do campo de estudos.

Poderíamos também tentar afirmar esta especificidade dos estudos de jornalismo aplicando o conceito de "campo científico" de Bourdieu, apresentando-o como "campo do jornalismo" ou, mais especificamente, "campo acadêmico do jornalismo" ou "campo científico do jornalismo" - se quisermos, cada vez mais, recortar e precisar o objeto. Tal conceito poderia ser adequado para, em uma perspectiva ampliada, identificar um conjunto articulado de atores (individuais e organizacionais, ligados à formação profissional, setor produtivo ou pesquisa científica), conhecimentos (conceitual-acadêmicos e normativo-profissionais) e práticas de atuação e inserção sociais. Como não consegue resolver os problemas lógicos da produção do conhecimento científico, o conceito de campo cientifico do jornalismo não pode ser definido, na perspectiva de Bourdieu, a partir do rigor epistemológico.

Assim, buscando uma opção outra para caracterizar a investigação do campo do jornalismo, poderíamos tentar dar forma aos estudos de jornalismo por meio da definição do conjunto de teorias que o integram (um dos termos mais usados para afirmar esta identidade particular é o de "Teorias do Jornalismo"). Aqui, uma grande dificuldade se torna evidente: como recortar uma teoria para afirmá-la ser "do Jornalismo" e não de outro fenômeno co- 
municacional. Por exemplo, a teoria do agendamento (ou agenda-setting) não pode ser descolada de sua aplicabilidade a uma multiplicidade de fenômenos e questões que transcendem ao jornalismo. Mesmo os estudos de produção de notícias (newsmaking), com um amplo e eficaz volume de investigações empírica sobre um objeto jornalístico particular, apresentam fundamentos, princípios e metodologias que se articulam a visões transversais ou modos comuns de olhar outras rotinas e processos de produção, com base nas ciências sociais.

É possível reconhecer, em alguns estudos sobre a notícia (FRANCISCATO, 2013), um esforço de constituição de um pensamento original que poderia sinalizar um caminho para a constituição de uma tradição de pesquisa nos estudos sobre jornalismo, por exemplo em obras como a de Lorenzo Gomis, Teoría del periodismo - Cómo se forma el presente (1991), e de Adelmo Genro Filho, O segredo da pirâmide: para uma teoria marxista do jornalismo (1987). Neles, compreender a notícia passa por constituir uma ordem discursiva original, própria, um núcleo comum de conceitos (acontecimento, atualidade, singularidade), em que o fator temporal é um dos principais elementos comuns às noções propostas.

A notícia, nesses autores, se destaca como fenômeno complexo não redutível nem igualável a outros fenômenos sociais. Ela é expressão específica de uma atividade singular que, em consequência, solicita uma construção conceitual específica, densificada. Tal elaboração, no entanto, não criou uma normatividade lógica de tratamento científico dos fenômenos jornalísticos para ser aceita como tradição de pesquisa. Outras pesquisas sobre a notícia fazem movimentos transversais, partem de outros pressupostos, sustentam-se em núcleos firmes de outras disciplinas ou campos do conhecimento, esforçando-se para solidificá-los.

\subsection{O modelo de rede triádica aplicado aos estudos sobre jornalismo}

O modelo reticular da racionalidade científica apresentado por Laudan possui um tripé (rede triádica) em que estão presentes três elementos que o autor considera fundamentais para avaliar a cientificidade e a capacidade de progresso científico: as teorias, os métodos e os objetivos (axiologia). Como esses três aspectos influenciam-se mutuamente, para os estudos em jornalismo ascenderem a um estatuto epistemológico mais vigoroso, problemas conceituais precisam ser resolvidos. Vamos listar alguns:

a) A diversidade de objetivos: as teorias do jornalismo visitam este campo de estudos com diferentes objetivos. Por exemplo, há estudos que veem no jornalismo 
uma práxis de conhecimento social: teoria e prática se articulam no jornalismo para formar, para a sociedade, um conhecimento de novo tipo, singular e fundamental para a vida em sociedade. Diferentemente, outros estudos observam o jornalismo (meramente) como objeto de pesquisa, um objeto manipulável pelo pesquisador, a ser abordado e escrutinado em uma situação de externalidade em relação aos princípios que regem o conhecimento daquela disciplina;

b) Aqui, há um duplo nível de problematização dos métodos de pesquisa em jornalismo. É necessário fazer inicialmente uma distinção entre; a) um método lógico, referindo-se ao âmbito da interpretação da realidade; b) um método técnico de investigação, considerando este "as manipulações analíticas através das quais o investigador procura assegurar para si condições vantajosas de observação dos fenômenos" (FERNANDES, 1972, p. 13). Lakatos e Marconi (1992) e Gil (1999) destacam dois níveis metodológicos: os métodos de abordagem, em que são apresentados os princípios lógicos de uma pesquisa (método dedutivo, indutivo, hipotético-dedutivo, dialético e fenomenológico); e os métodos de procedimento, em que são explicitadas as opções de trabalho do pesquisador conforme o problema e o objeto de pesquisa. Neste, encontram-se o método histórico, estatístico, comparativo, tipológico, etnográfico, experimental, entre outros.

Assim, pensar na possibilidade de que, em uma rede triádica na perspectiva de Laudan, os métodos justificam as teorias e estas, por sua vez, limitam as opções metodológicas, exige considerar o grande desafio, dos estudos em jornalismo, de desenvolver as duas dimensões do método citadas acima. Há a necessidade de considerar a preocupação de Huutoniemi et al (2010) quando este autor indica que a perspectiva interdisciplinar é uma atividade integradora, geradora de intersecções para além das fronteiras, o que demandaria uma integração ou combinação densa entre diferentes aplicações metodológicas.

c) A multiplicidade das teorias que abordam o jornalismo. Tal aspecto poderia nos dar uma primeira impressão de riqueza aos estudos em jornalismo, pelo grande volume de disciplinas que penetram em espaços de interlocução acadêmica voltados à pesquisa em jornalismo. Entretanto, esse mesmo elemento indica desafios e fragilidades, porque dificulta a constituição das tradições de investigação. Há normas epistêmicas e metodológicas próprias e consensuais à comunidade de pesquisadores em jornalismo? Temo dizer que não, embora os fóruns de discus- 
são sinalizem alguns consensos mínimos que se formam a partir de preocupações e movimentos teóricos que se alternam com razoável amplitude.

Algumas obras recentes têm procurado, inclusive, indicar o potencial epistemológico do campo nomeando-o como "Teorias do Jornalismo" e elaborando uma tipologia de abordagens que estudam o jornalismo por diferentes perspectivas. Como, no entanto, não convergem para consensos mínimos, são também indicativos de fragilidades do campo.

\section{Considerações finais}

A visitação a autores de uma perspectiva de história e filosofia da ciência nos permitiu situar, com mais amplitude, alguns problemas que perpassam a constituição dos estudos de jornalismo. É aceito que o jornalismo, por se tratar de um fenômeno complexo e profundamente entranhado no cotidiano das sociedades, demanda um tratamento multidisciplinar. Em consequência, devido a um esforço de construção do campo acadêmico do jornalismo, esta presença de múltiplas disciplinas tem sido sistematizada na forma de "Teorias do Jornalismo", o que gera identidade acadêmica e institucional, mas não supera as tensões entre estes elementos.

Uma das raízes dessas tensões tem sido, por exemplo, a ausência de um eixo condensador da construção teórica e empírica, como explicitado no conceito de "tradições de pesquisa". Sem este reconhecimento e preservação, conceitos fundamentais são expostos e colocados em dúvida ou suspensão, não permitindo uma consolidação epistemológica dos estudos de jornalismo.

Ao recorrermos a Laudan, encontramos sua formulação da "resolução de problemas" como expressão profícua para considerar os estudos de jornalismo. Este tem sido um movimento dos pesquisadores em jornalismo a partir de reconhecimentos de demandas empíricas do mundo social e, em alguns casos, alcançando um nível de formulação teórica bastante sofisticada. Ao mesmo tempo, a perspectiva de Laudan, caso fosse adotada, exigiria tornar mais rigoroso e sofisticado o tratamento das interações disciplinares nos estudos de jornalismo, bem como a percepção de que tradições de pesquisa orientam as construções teóricas para, assim, superar as tensões decorrentes de encontros e cruzamentos disciplinares. 


\section{Referências}

BERGER, Christa.; MAROCCO, Beatriz. (Org.). A era glacial do jornalismo: teorias Sociais da Imprensa. Porto Alegre: Sulina, 2008. v. 2.

BOLAÑO, César. A centralidade da chamada Economia Política da Comunicação (EPC) na construção do campo acadêmico da comunicação: uma contribuição crítica. In.: BOLAÑO, C. (org.). Comunicação e a crítica da economia política: perspectivas teóricas e epistemológicas. São Cristóvão: Editora UFS, 2008. p. 97-112

BOURDIEU, Pierre. Para uma sociologia da ciência. Lisboa: Edições 70, 2004.

FERNANDES, Florestan. Fundamentos empíricos da explicação sociológica. São Paulo: Editora Nacional, 1972.

FRANCISCATO, Carlos E. As fronteiras dos estudos sobre jornalismo: uma análise a partir da notícia como objeto de estudo. In: Encontro Anual da Compós, 22, 2013, Salvador. Anais... Salvador: Universidade Federal da Bahia, 2013, p. 1-18.

GENRO FILHO, Adelmo. 0 segredo da pirâmide: para uma teoria marxista do jornalismo. Porto Alegre: Tchê Editores, 1987.

GIDDENS, Anthony. Novas regras do método sociológico: uma crítica positiva das sociologias compreensivas: Lisboa: Gradiva, 1996.

GIL, Antônio Carlos. Métodos e técnicas de pesquisa social. 5. ed. São Paulo: Atlas, 1999. GOMIS, Lorenzo. Teoría del periodismo: cómo se forma el presente. Barcelona: Paidós, 1991.

GROTH, Otto. 0 poder cultural desconhecido: fundamentos da ciência dos jornais. Petrópolis: Vozes, 2011.

HOHLFELDT, Antonio. Discutir as relações e não a eventual falta de identidade da comunicação social com outros campos de conhecimento. E-compós, 2004. Disponível em: $<$ http://www.compos.org.br/seer/index.php/e-compos/article/viewFile/16/17>. Acesso em 12 ago. 2012.

HUUTONIEMI, Katri et al. Analyzing interdisciplinarity: typology and indicators. Research Policy, San Francisco (USA), v. 39, p. 79-88, 2010.

KUHN, Thomas. A estrutura das revoluções científicas. 9. ed. São Paulo: Perspectiva, 2009.

LAKATOS, E. M,; MARCONI, M. Metodologia do Trabalho Científico. 4. ed. São Paulo, Ed. Atlas, 1992.

LAKATOS, Imre. La metodología de los programas de investigación científica. Madrid: Alianza, 1989. 
LAUDAN, Larry et al. Mudança científica: modelos filosóficos e pesquisa histórica. Estudos Avançados, São Paulo, v. 7, n.19, p. 7-84, 1993.

LAUDAN, Larry et al. El progreso y sus problemas: hacia una teoría del progreso científico. Madrid: Encuentro, 1986.

LÖFFELHOLZ, Martin; ROTHENBERGER, Liane. Continuum eclético, disciplina distinta ou subdomínio dos estudos de comunicação?: considerações teóricas e conclusões empíricas a respeito da disciplinaridade, multidisciplinaridade e transdisciplinaridade dos estudos de jornalismo. Brazilian Journalism Research, Brasilia, v. 7, n.1, p. 7-31, 2011.

MAROCCO, Beatriz; BERGER, Christa. (Org.). A era glacial do Jornalismo: teorias Sociais da Imprensa. Porto Alegre: Sulina, 2006. v. 1.

MARTINO, Luiz. As epistemologias contemporâneas e o lugar da Comunicação. In: LOPES, Maria Immacolata V. (Org.). Epistemologia da Comunicação. São Paulo: Loyola, 2003.

OSTERMANN, Fernanda et al. Tradição de pesquisa quântica: uma interpretação na perspectiva da epistemologia de Larry Laudan. Revista Electrónica de Enseñanza de las Ciencias, Vigo (Espanha), v. 7, n. 2, p. 366-386, 2008.

PESA, Marta A.; OSTERMANN, Fernanda. La Ciencia como actividad de resolución de problemas: la epistemologia de Larry Laudan y algunos aportes para las investigaciones educativas en ciencias. Caderno Brasileiro do Ensino de Física, Florianópolis, v. 19, n. especial, p. 84-99, jun. 2002.

ROMANCINI, Richard. 0 campo científico da comunicação no Brasil: institucionalização e capital científico. 2006. Tese (Doutorado em Ciências da Comunicação) - Escola de Comunicação e Artes, Universidade de São Paulo, São Paulo, 2006.

SOUZA, Jorge Pedro. Pesquisa em jornalismo: o desbravamento do campo entre o século XVII e o século XIX. bocc - Biblioteca On-line de Ciências da Comunicação. 2007. Disponível em: <http://www.bocc.ubi.pt/pag/sousa-jorge-pesquisa-em-jornalismo.pdf $>$. Acesso em: 5 de jan. 2010.

ZELIZER, Barbie. Taking journalism seriously. Thousand Oaks: Sage, 2004. 


\title{
New perspectives for a systematization of journalism theories
}

\begin{abstract}
Studies of journalism have at least a century of regular scientific production, although their place in the academic world still depends on institutional disputes and questions about its constitution as a theoretical framework, discipline or field of study. If, on one hand, the discussion has epistemological roots regarding elements which give strength, density and convergence to theories, it is also possible to conduct this reflection looking at the historical formation and configuration of these studies. The purpose of this article is to make a double movement through journalism studies: understanding this historical movement, its roots and trajectories; then consider a contemporary perspective, based on questions about its disciplinarity. This work operates a theoretical and conceptual systematization of more general trends of these studies, based on a reference bibliography in journalism.
\end{abstract}

\section{Keywords}

Theories of Journalism. History of Science. Disciplinarity. Scientific field. Scientific progress.

Recebido em 16/09/2015

Aceito em 02/12/2015 